\title{
Monitoring in vivo reversible cysteine oxidation in proteins using ICAT and mass spectrometry
}

Sarela García-Santamarina ${ }^{1}$, Susanna Boronat ${ }^{1}$, Alba Domènech ${ }^{1}$, José Ayté ${ }^{1}$, Henrik Molina ${ }^{2}$ and Elena Hidalgo ${ }^{{ }^{*}}$

${ }^{1}$ Oxidative Stress and Cell Cycle Group, Departament de Ciències Experimentals i de la Salut, Universitat Pompeu Fabra, C/ Dr. Aiguader 88, E-08003 Barcelona, Spain

${ }^{2}$ The Rockefeller University Proteomics Resource Center, 1230 York Avenue, Box 105, New York, NY 10065, USA

${ }^{*}$ Corresponding author: Elena Hidalgo, Universitat Pompeu Fabra, C/ Dr. Aiguader 88, E-08003 Barcelona, Spain (elena.hidalgo@upf.edu; Tel: 34-93-316-0848; Fax: 34-93-316-0901) 


\section{ABSTRACT}

Reversible thiol oxidation of cysteine residues occurs in many intracellular catalytic and signalling processes. Here we describe an optimized protocol, which can be completed in approximately 5 days, to unambiguously identify specific cysteine residues which are transiently and reversibly oxidized, comparing two complex biological samples, obtained from yeast cell cultures, at the proteome level. After 'freezing' the in vivo thiol stage of cysteine residues by media acidification, we first block reduced thiols in extracts with iodoacetamide, and then we sequentially reduce and label reversible oxidized thiols with the biotin-based heavy or light iodoacetamide-derivatives, known as isotope-coded affinity tag (ICAT) reagents, so that the two samples can be compared at once after combination of the labelled extracts, trypsin digestion, streptavidin-affinity purification of peptides containing oxidized cysteines, liquid chromatography and mass spectrometry analysis (LC-MS/MS). For the same protein extracts, prior to cysteinecontaining peptide enrichment, individual relative protein concentrations are obtained by stableisotope dimethyl labelling.

Ontology:

Biological sciences / Biological techniques / Proteomic analysis

Biological sciences/Chemical biology/Post-translational modifications/thiol oxidation

\section{Categories:}

Chemical modification; Proteomics; thiol oxidation

Keywords: thiol oxidation / disulfide proteome / ICAT / dimethyl labelling / thioredoxin / $\mathrm{H}_{2} \mathrm{O}_{2}$

Is-protocol-to

Garcia-Santamarina, S. et al. The oxidized thiol proteome in fission yeast--optimization of an ICAT-based method to identify H2O2-oxidized proteins. J Proteomics $74,2476-86$ (2011). 
Garcia-Santamarina, S. et al. Is oxidized thioredoxin a major trigger for cysteine oxidation?

Clues from a redox proteomics approach. Antioxid Redox Signal 18, 1549-56 (2013).

Is-related-to

Boersema, P. J., Raijmakers, R., Lemeer, S., Mohammed, S. \& Heck, A. J. Multiplex peptide stable isotope dimethyl labeling for quantitative proteomics. Nat Protoc 4, 484-94 (2009). 


\section{INTRODUCTION}

Thiols of cysteine residues in proteins are common targets of intracellular oxidation. The deprotonated thiolate anion of cysteine is the reactive group and this the predominant form at physiological or higher $\mathrm{pH}^{1}$. Two-electron oxidants, such as the reactive oxygen species (ROS) and second messenger hydrogen peroxide $\left(\mathrm{H}_{2} \mathrm{O}_{2}\right)$, generate sulfenic acid $(\mathrm{SOH})$ as their initial oxidation product. In the presence of available proximal thiol groups, $\mathrm{SOH}$ can form intra- or inter-molecular disulfide bonds, or mixed disulfides with glutathione (GSH) ${ }^{2}$ or cysteine ${ }^{3,4}$. $\mathrm{SOH}$ can also react with vicinal nitrogens, for example in protein tyrosine phosphatases ${ }^{5,6}$, to form sulfenamides. In the presence of excess oxidants, $\mathrm{SOH}$ can be irreversibly oxidized to sulfinic $\left(\mathrm{SO}_{2} \mathrm{H}\right)$ or sulfonic $\left(\mathrm{SO}_{3} \mathrm{H}\right)$ acids ${ }^{7,8}$. Also, both thiols in proteins and low molecular weight thiols, including GSH, cysteine and homocysteine, can undergo S-nitrosylation (SNO) mediated by nitric oxide (NO) and its metabolites [including reactive nitrogen species (RNS)] ${ }^{9}$. Non-toxic reversible oxidations ( $\mathrm{SOH}, \mathrm{S}-\mathrm{S}$, mixed S-S or SNO) are used as regulatory switches in enzymatic reactions such as the one catalyzed by ribonucleotide reductase, and the oxidized proteins can either directly or indirectly be reduced by potent intracellular redox buffers, the thioredoxin ( $\mathrm{Trx}$ ), the GSH/glutaredoxin systems, and the GSH/S-nitrosoglutathione reductase (GSNOR) system ${ }^{10-13}$. Moreover, redox sensitive proteins undergo reversible thiol oxidations to participate in electron flow pathways and/or trigger signalling cascades ${ }^{8,14}$. Proteins respond to localized changes in NO concentrations by protein targeted S-nitrosylation or denitrosylation ${ }^{15-17}$. Understanding the effects of environmental variations, of ROS- or RNSmediated molecular mechanisms, as well as of genetic disparities on global reversible cysteine oxidations is crucial to obtain more insight into redox signalling events, which eventually modulate many essential intracellular processes.

\section{Electrophoretic proteomic approaches for looking at thiol oxidation/reduction}

Several proteomic approaches have been undertaken to assess the in vivo global redox changes of thiol proteomes in different cellular backgrounds or upon oxidative stress. One method, termed diagonal SDS-PAGE, was adapted to identify cytoplasmic proteins which undergo disulfide bond formation after cell exposure to oxidative stress ${ }^{18}$. This methodology 
consists on separating oxidized proteins in a first dimension by non-reducing electrophoresis, with further separation on a second electrophoretic dimension under reducing conditions. Proteins containing disulfide bonds, other than those containing intra molecular disulfides not critically affecting their 3D structure, will migrate out of the diagonal of the $2 \mathrm{D}$ gels.

The biotin switch assay, initially developed to detect protein S-nitrosylation ${ }^{19}$, has also been used to study disulphide bonds and other types of reversible thiol oxidations. With the biotin switch, cysteine oxidation is detected as an increase in the concentration of the cysteinecontaining peptide. Initial reduced cysteines are blocked with an alkylating agent [iodoacetamide (IAM) or maleimide]. Reversibly oxidized thiols are then reduced and the newly appearing reduced cysteines are alkylated with IAM- or maleimide-based biotin derivatives. In the original biotin switch assay, protein SNOs were differentiated from the rest of reversible thiol modifications by using ascorbate as a reducing agent (later improved to the more specific combination of ascorbate/ $\mathrm{CuCl}_{2}{ }^{20}$ ). However, by modifying the nature of the reducing agent used, other types of thiol modifications can be detected. Hence, sulfenated cysteines can be specifically detected upon reduction with arsenite ${ }^{21}$, Grx specifically reduces S-glutathionylated cysteines $^{22}$, and general reversibly oxidized thiols can be detected upon incubation with dithiothreitol (DTT) of (tris-(2-carboxyethyl)phosphine) (TCEP). In these strategies, biotin allows sample enrichment by affinity purification, with notable improvements in sensitivity and specificity. This approach, in combination with 2D electrophoresis, allowed to successfully detect many redox-sensitive proteins in different organisms, including bacteria ${ }^{23}$, yeast ${ }^{24}$ and cells from higher eukaryotes ${ }^{25}$.

However, these procedures still have to cope with the intrinsic limitations of a technique such as $2 \mathrm{D}$ electrophoresis, including lack of specificity and sensitivity ${ }^{26}$. Moreover, these methodologies are semi-quantitative, at best, and they do not allow the identification of the specific oxidized cysteine residues within the polypeptide.

\section{Proteomic approaches using LC-MS}

In the last few years, there has been an incredible development of the proteomics field, including quantitative proteomics, which consequently affected the development of the redox proteomics area. Thus, new methodologies were designed to detect and quantify to different extents reversible thiol modifications. 
One of these, SNO Site Identification (SNOSID) is the extension of the biotin switch methodology that allows high-throughput identification of SNO sites on proteins ${ }^{27}$. This modified approach includes the addition of a proteolytic step prior to avidin enrichment, allowing the selective isolation of only those peptides previously containing a SNO modification. Then, an inventory of SNO-cysteines in proteins is obtained upon nanoflow liquid chromatography (nLC) tandem MS (nLC-MS/MS). By changing the alkylating agents to $d_{0}$-NEM (first alkylation step) and $d_{5}$-NEM (second alkylation step) an improved $d$-Switch method allowed the quantification of the absolute ratio of free $\mathrm{SH}$ versus $\mathrm{SNO}$ on individual cysteine containing peptides ${ }^{28}$. Still, due to the labile nature of the SNO modification, these indirect methodologies are nowadays being challenged by new experimental approaches involving the direct reaction of SNOs with phosphine derivatives (reviewed in ${ }^{29,30}$ ).

GELSILOX was designed to obtain a general quantification of reduced and oxidized cysteines as well as protein abundance in the same experiment ${ }^{31}$. In this approach, proteins from two samples to be compared are treated in parallel, in the presence of SDS, with an alkylating agent. Then, SDS-PAGE is performed with the alkylated extracts up to the formation of a single band containing the whole proteome. This allows protein immobilization and the use of the gel as a reaction chamber to then get rid of SDS, reduce reversible oxidized thiols, alkylation of former oxidized thiols with a second alkylating agent, and protein trypsinization. Trypsinized peptides are then eluted from the gel and labelled with either ${ }^{16} \mathrm{O}$ or ${ }^{18} \mathrm{O}$. Non cysteine containing peptides are used to quantify relative protein abundance, and cysteinecontaining peptides are quantified in their initial redox status.

The use of the quantitative isotope coded affinity tag (ICAT) technology ${ }^{32}$ paved the way for the development of gel-free approaches combined with stable isotope labeling applied to redox proteomics ${ }^{33-35}$. ICAT moieties contain the cysteine alkylating agent IAM linked to a biotin tag through a cleavable 9 -carbon linker, which exists in an isotopically light $\left({ }^{12} \mathrm{C}\right.$-ICAT) and a 9-Da-heavier isotopically heavy form $\left({ }^{13} \mathrm{C}-\right.$ ICAT $)$. ICAT reagents have been used in three ways (see below): (i) labelling of reduced and oxidized thiols within the same biological sample with the heavy and light ICAT forms, or OxICAT ${ }^{23}$; (ii) use of the reagents to label reduced thiols of two different biological samples, the decrease of reduced thiols being an indicator of 
cysteine oxidation ${ }^{33}$; and (iii) labelling of oxidized thiols of two biological samples with the ICAT reagents ${ }^{36-38}$. This last strategy is the one described here.

\section{The OxICAT approach}

In the OxICAT methodology, initially reduced cysteines are labelled with light ICAT, whereas upon reduction, newly appearing reduced cysteines are labelled with heavy ICAT. This strategy has successfully been applied to detect cysteine oxidations in E. coli ${ }^{23}$, yeast ${ }^{39}$, and C. elegans ${ }^{40,41}$. However, as $\sim 90 \%$ of intracellular cysteines are in their reduced state ${ }^{37}$, for most of the cysteine-containing peptides there is a big disproportion between the relative abundances of the oxidized versus the reduced forms of the same peptides. Still, in order to be quantified, both forms of the peptide have to be enriched and then their relative abundances compared, which in most of the cases will differ in several orders of magnitude. To fish those low abundant peptides and to perform a comprehensive analysis, samples require extensive fractionation [up to 192 liquid chromatography (LC) fractions] ${ }^{23} 39-41$ and much instrumentation availability. Another pitfall of this methodology is the large amounts of ICAT reagents required to detect not only oxidized but also reduced thiols in each biological sample, which raises the price of the procedure.

\section{Our ICAT-based proposal}

An alternative approach is to label reduced or oxidized thiols of two different samples, and compare them at once. We are here describing the use of ICAT labelling to compare the reversibly oxidized thiol-proteome of two samples at once (Fig. 1). This approach has been successfully applied to detect reversible cysteine oxidations in the yeast Schizosaccharomyces pombe upon different genetic and environmental conditions. Thus, we have used it to compare pair-wised the thiol proteomes of wild-type cells treated or not with $\mathrm{H}_{2} \mathrm{O}_{2}{ }^{37}$, or of wild-type cells versus mutants with defects in the thioredoxin system ${ }^{38}$. It is worth mentioning that this protocol should be easily optimized for studying the thiol proteomes of other cell types.

Reduced thiols are initially blocked with IAM, an inexpensive reagent which will titrate the majority of reduced intracellular thiols, which are the majority of thiols in a given proteome $\left(>90-95 \%{ }^{37}\right)$. After reduction of reversible oxidized thiols, newly appearing thiols are labelled in one of the samples with the light ICAT reagent and in the other one with the heavy ICAT 
reagent. Upon labelling, the two samples are mixed in equal ratios, trypsinized, affinity purified and analyzed by LC-MS/MS. For each peptide, a ratio of cysteine oxidation (ICAT ratio) is obtained by comparing the abundance of a particular peptide in one sample with the levels of the same peptide in the other sample. In this case, since only those peptides containing reversible oxidized thiols in both samples are labelled with ICAT reagents, the amount of cysteines labelled with either ICAT reagent is approximately of the same order of magnitude, providing a sample with lower level of complexity. Thus, sample fractionation is not required, which accelerates and simplifies the whole process, including data analysis. To distinguish between changes in amount of protein versus changes in the redox state of a particular cysteine, we propose that protein quantification of non-enriched peptides is included in this analysis. Mass spectrometry-based relative protein quantification can be carried out by either label free quantification or by using a stable isotope-based strategy (for a review, see ${ }^{42}$ ). In this protocol we suggest stable isotope-based relative protein quantification using dimethyl labelling as described by Boersema et al. ${ }^{43}$ because this technique is inexpensive, simple and robust and provides workflows comparable to the ICAT-based quantification. Because of expected high complexity of this non-enriched sample, we suggest fractionation by e.g. micro anion exchange as described by Wiśniewski et $a^{53}$. It is worth mentioning, however, that alternative to dimethyl labelling other stable isotope-based strategies such as TMT or ITRAQ can be used for relative protein quantification. Thus, by combining ICAT labelling with dimethyl labelling we are able to obtain a more complete picture at a proteomic level of relative reversible cysteine oxidations in two samples to be compared, taking into account changes in the steady-state amounts of individual proteins. It is worth mentioning that our method does not provide information about the percentage of oxidation for a particular protein within each biological sample; to overcome this limitation, we previously proposed a method to validate the ICAT results, which can also be used to quantify the amount of oxidation for individual oxidized proteins, based on the in parallel labelling for each sample of reduced and oxidized thiols with a biotin-linked reversible alkylating agent, and subsequent release of enriched proteins from streptavidin-sepharose beads for Western blot-analysis with specific antibodies ${ }^{37}$. In Table 1 there is a brief description of the strengths and weakness of the different methodologies mentioned in the Introduction weighed against our ICAT-based proposed method for studying 
reversible thiol oxidations. It is worth mentioning that while the reviewing process of this article was in progress, Smith and Qian have reported another gel-free methodology based on the direct binding of originally oxidized cysteines to a thiol-binding resin.$^{44}$ We believe we provide to the community a robust methodology to quantify with high sensitivity and quantitative accuracy cysteine oxidations in two samples to be compared at once.

Table 1 | Comparison of our ICAT-based methodology with other methodologies mentioned in the Introduction

\begin{tabular}{lll}
\hline \multicolumn{1}{c}{ Technique } & \multicolumn{1}{c}{ Strengths } & \multicolumn{1}{c}{ Weakness } \\
\hline Diagonal electrophoresis & $\begin{array}{l}\text { Exclusive detection of } \\
\text { disulphide-bonded proteins }\end{array}$ & $\begin{array}{l}\text { 2D-gel based: lack of sensitivity } \\
\text { No identification of the cysteine carrying the } \\
\text { oxidative modification } \\
\text { No quantitative }\end{array}$ \\
\hline $\begin{array}{l}\text { Gel-based variants of the } \\
\text { biotin switch approach }\end{array}$ & $\begin{array}{l}\text { Adaptable to detect different } \\
\text { forms of reversible thiol } \\
\text { oxidations }\end{array}$ & 2D-gel based: lack of sensitivity \\
& $\begin{array}{l}\text { No identification of the cysteine carrying the } \\
\text { oxidative modification } \\
\text { No quantitative }\end{array}$ \\
\hline SNOSID & $\begin{array}{l}\text { Only detection of SNO } \\
\text { cysteines } \\
\text { Increased sensitivity compared } \\
\text { to 2D-gel based approaches } \\
\text { (including the original biotin } \\
\text { switch approach) }\end{array}$ & $\begin{array}{l}\text { No quantitative } \\
\text { SNO of cysteines is a labile modification, } \\
\text { possible loss during protocol performance }\end{array}$ \\
\hline
\end{tabular}

d-Switch method

GELSILOX

OXICAT
Only detection of SNO cysteines

Quantitative: reflects the amount of SNO modified cysteine compared with reduced cysteine Not affected by changes in protein concentration

Fully quantitative: provides quantitative data of reduced and oxidized cysteine, as well as of protein abundance in a single experiment Detection of general reversible oxidized thiols

Quantitative: reflects the exact proportion of reversibly oxidized versus reduced cysteine in all peptides

Not affected by changes in protein concentration

Detection of general reversible oxidized thiols
SNO of cysteines is a labile modification, possible loss during protocol performance

Analysis of one condition at a time
No information available regarding

biological reproducibility

Complex analysis of the data

Complex analysis of the data

Analysis of one condition at a time

Extensive sample fractionation

Complex and time consuming analysis of the data 
Our ICAT-based

proposed method

\section{Quantitative}

High sensitivity and accuracy quantification of cysteine containing peptides

Comparison of two samples at once

Detection of general reversible oxidized thiols
Additional step of protein quantitation

No information about the relative abundances of reduced versus oxidized cysteine for each peptide

\section{Experimental design}

The present gel-free, ICAT-adapted biotin switch assay has been developed to identify, compare and quantify reversible cysteine oxidations in two biological samples at the peptide level. This is an easy-to-follow protocol which overcomes most limitations of previous methodologies, such as the gel-based approaches or the OxICAT technique.

Several are the key points of the setup providing the best results:

Trapping the redox state of the thiols Due to the highly reactive nature of the thiolate anion, a major difficulty at the time of studying reversible cysteine oxidations is to obtain a snapshot of the in vivo cysteine redox status (for a review, see ${ }^{45}$ ). Cell permeable alkylating agents have been often use to trap the redox state of thiols during sample preparation, but incomplete thiol alkylation in vivo have been demonstrated both for $\mathrm{N}$-ethylmaleimide ${ }^{22,46}$ and IAM $^{47}$. In our approach trichloroacetic acid (TCA) is added to the cell media instead. TCA not only rapidly protonates all redox-active thiolate anions by shifting the $\mathrm{pH}$ below their $\mathrm{p} K_{\mathrm{a}}$, but also stops thiol-disulfide exchanges by precipitating and denaturing proteins ${ }^{23,48}$. It is considered that there is a decrease of at least 10 -fold in the thiol-disulfide shuffling reaction rates per each $\mathrm{pH}$ unit below the cysteine $\mathrm{p} K_{\mathrm{a}}$ value. Addition of TCA to the cell media prior to cell collection is especially relevant to obtain a real snapshot of transient thiol proteomes, such as the ones arising upon environmental $\mathrm{H}_{2} \mathrm{O}_{2}$ treatments. In a later step (see point 3), IAM will be used to irreversibly modify reduced thiols. As a control to demonstrate the importance of using this combined strategy (TCA followed by alkylating agent) as opposed to the use of only an alkylating agent, we analyzed the redox state of Pap1, an S. pombe transcription factor which Cys residues are transiently oxidized upon $\mathrm{H}_{2} \mathrm{O}_{2}$ treatments. As shown in

Supplementary Figure 1, the full in vivo transition from a reduced to an oxidized state in Pap1 
is only preserved when the combined strategy is applied. Since some reports indicate that TCA precipitations may be slightly inefficient and introduce variability in the concentrations of the biological samples ${ }^{49-51}$, we strongly suggest to perform steps involving TCA precipitation carefully. Protein concentration may be checked after each precipitation step to follow up uncontrolled loses.

Pilot experiment using 1D electrophoresis Prior to use the ICAT-based proteomic methodology to interrogate different oxi-proteomes, we strongly encourage the fluorescent labelling of oxidized thiols in TCA extracts followed by fluorescent scanning of 1D gels as a pilot experiment (see below, 'Anticipated results' and Figure 2a) ${ }^{37}$.

Amount of protein required for analysis The starting protein amount in each sample is recommended to be about $2 \mathrm{mg}$. With this amount of protein, a single vial of ICAT reagent per sample will suffice to extensively label all reversibly oxidized cysteines in the samples, which only account for less than $5 \%$ of total cellular thiols ${ }^{37}$.

Blocking reduced thiols

We recommend excess IAM to initially block all reduced thiols in extracts (ie. for $2 \mathrm{mg}$ of protein we use $100 \mathrm{mM}$ IAM in a volume of $0.5 \mathrm{ml}$ ) instead of other alkylating agents such as $\mathrm{N}$-ethylmaleimide. In general, alkylation rates by $\mathrm{N}$ ethylmaleimide are faster than those of IAM especially at low $\mathrm{pHs}^{45,47}$. The reason for choosing IAM is that not only reduced thiols will be blocked with IAM, but also other sites prone to unspecific alkylation (IAM can also alkylate amines from lysines and $\mathrm{N}$-terminal positions ${ }^{52}$, thioethers in methionines ${ }^{53,54}$, imidazoles in histidines ${ }^{55}$ and carboxylates from aspartate and glutamate ${ }^{52}$. ICAT reagents are IAM derivatives, and they are expected to display similar unspecific alkylation properties such as the ones described for IAM. By using IAM as a first blocking reagent, we ensure only specific cysteine labelling of newly reduced thiols with the IAM-based ICAT reagents in the second alkylation step.

Use of buffers TCA is extensively used along the whole protocol, either to initially freeze the in vivo thiol oxidation status or for protein precipitation between labelling and reducing steps. For this reason, we strongly recommend buffering the alkylating and the reducing steps with $200 \mathrm{mM}$ Tris-HCl pH 8.5. pH should be checked in each step with standard $\mathrm{pH}$ strips. A denaturing buffer is also recommended, $6 \mathrm{M}$ urea, to maximize accessibility to the 
solvent containing the alkylating agent and minimize artifactual alkylations due to oxidation being faster than the alkylation step.

Non-specific reduction of reversible cysteine oxidations After reduced thiol titration with IAM, we propose the use of tris (2-carboxyethyl) phosphine hydrochloride (TCEP) to non-specifically reduce all reversible cysteine oxidations.

Determining protein concentration Upon reduction with TCEP, and prior to protein precipitation with TCA, protein concentration in the samples has to be determined by Bradford assay and then equalized between samples. From this step, $100 \mu \mathrm{g}$ of each sample are withdrawn to determine individual protein concentrations by dimethyl labelling; see Figure 1, right panel, Dimethyl protein quantification (DM). The rest of the equalized samples are then TCA precipitated for labelling with the ICAT reagents.

Buffer composition for trypsin digestion Since the ICAT buffer contains $6 \mathrm{M}$ urea, after mixing light and heavy ICAT reactions, they must be diluted down to $<1 \mathrm{M}$ urea for good trypsin digestion. The $10 \mathrm{mM} \mathrm{CaCl}_{2}$.provided by the ICAT kit (AB Sciex, Foster City, CA, USA) can be used for the dilution.

LC-MS/MS analysis of mixed ICAT sample, and number of biological replicates If sample amount permits subject the sample to multiple LC-MS/MS analyses. Increasing the number of LC-MS/MS analyses often increases the number of matched peptides and, particular important for the ICAT samples where many oxidized thiols only will exist in one particular peptide, allows for multiple measurements of the same peptides. An alternative would be to use multiple proteases. This can generate different peptides containing the same cysteine and/or peptides containing oxidized thiols not accessible by trypsin. If biological or/and technical replicates are carried out it is recommended to switch the light and heavy ICAT reagents (label swap) ${ }^{56}$. Regarding the number of biological replicates, we suggest to use two or three per each condition, one of them with label swapping.

Normalizing the Cys oxidation/protein ratios Normalize individual ICAT and dimethyl ratios for each condition by dividing each of those ratios by the median value of all dimethyl ratios obtained for the same condition (Fig. 2b). This will correct bias due to different protein loading, errors in measuring protein concentrations or sample losses. . 


\section{MATERIALS}

\section{REAGENTS}

- $\quad$ Trichloroacetic acid (TCA) (Merck-Millipore, Darmstadt, Germany, cat. no. 1008070250) CAUTION Exposure causes corrosion in eyes, skin and lungs. When handling, wear appropriate protective eyewear, gloves and clothing.

- $\quad$ Glass beads, 0.4-0.6 mm (Sartorius Stedim Biotech, Goettingem, Germany, cat. no. BBI-8541701).

- $\quad$ Acetone (Merck-Millipore, cat. no. 1000142511) CAUTION Exposure causes irritation in eyes, skin and respiratory tract. When handling, wear appropriate protective eyewear, gloves and clothing.

- $\quad$ Iodoacetamide (IAM) (Sigma-Aldrich, St. Louis, MO, USA, cat. no. I1149) CAUTION Toxic if swallowed. Exposure causes irritation in eyes, skin and respiratory tract. When handling, wear appropriate protective eyewear, gloves and clothing.

- $\quad$ Tris(hydroxymethyl)aminomethane (Tris base) (Sigma-Aldrich, cat. no. T1378)

CAUTION Toxic if swallowed. Exposure causes irritation in eyes, skin and respiratory tract. When handling, wear appropriate protective eyewear, gloves and clothing.

- Hydrochloric acid (HCl) (Merck-Millipore, cat. no. 1003172500) CAUTION Exposure causes corrosion in eyes, skin and lungs. When handling, wear appropriate protective eyewear, gloves and clothing.

- $\quad$ Urea (Merck-Millipore, cat. no. 1084881000) CAUTION Exposure causes irritation in skin and eyes. When handling, wear appropriate protective eyewear, gloves and clothing.

- $\quad$ Ethylenediamine tetraacetic acid disodium salt (EDTA) (Sigma-Aldrich, cat. no. E5134) CAUTION Exposure causes irritation in eyes, skin and respiratory tract. When handling, wear appropriate protective eyewear, gloves and clothing.

- $\quad$ Sodium dodecyl sulphate (SDS) (Sigma-Aldrich, cat. no. L4390) CAUTION Flammable. Exposure causes irritation in eyes, skin and respiratory tract. When handling, wear appropriate protective eyewear, gloves and clothing. Prepare solutions in a fume hood. 
CAUTION Exposure may cause irritation in eyes, skin and respiratory tract. When handling, wear appropriate protective eyewear, gloves and clothing.

- Bradford protein assay (BioRad, Hercules, CA, USA, cat. no. 500-0006) CAUTION Toxic by inhalation, in contact with skin and if swallowed. It causes burns. When handling, wear appropriate protective eyewear, gloves and clothing.

- $\quad$ Acetonitrile (ACN). (Sigma-Aldrich, cat. no 34998) CAUTION Flammable liquid and vapour. Exposure causes irritation in eyes and respiratory tract and blood system damage. When handling, wear appropriate protective eyewear, gloves and clothing.

- $\quad$ Cleavable ICAT Reagent-10 assay kit (AB Sciex, Foster City, CA, USA, cat. no. 4339036). Contains all of the necessary reagents, buffers, cartridges and instructions with appropriate MSDS data. It contains 10 units of Heavy Cleavable ICAT® Reagent and 11 units of Light Cleavable ICAT® Reagent. Each unit of reagent will label approximately all reduced cysteines contained in $100 \mu \mathrm{g}$ of protein extract.

- $\quad$ Dithiothreitol (DTT) (Sigma-Aldrich, cat. no. D0632) CAUTION Toxic if swallowed. Exposure causes irritation in eyes, skin and respiratory tract. When handling, wear appropriate protective eyewear, gloves and clothing.

- $\quad$ Calcium chloride $\left(\mathrm{CaCl}_{2}\right)$ (Sigma-Aldrich, cat. no 499609) CAUTION Irritating to the eyes, to the skin, nose, throat and lungs. When handling, wear appropriate protective eyewear, gloves and clothing.

- $\quad$ TPCK-treated trypsin (AB Sciex) CAUTION Exposure causes irritation in eyes, skin and respiratory tract. When handling, wear appropriate protective eyewear, gloves and clothing. - $\quad$ Formic acid (Sigma-Aldrich, cat. no. 695076) CAUTION Exposure causes burns in eyes, skin and respiratory tract. It is harmful if inhaled, and may cause allergic reactions. It is a flammable liquid and vapour. When handling, wear appropriate protective eyewear, gloves and clothing. Keep away from sources of heat, sparks and flames.

- $\quad$ Sequencing grading trypsin (Promega, Madison, WI, USA, cat. no. V5111) CAUTION

Exposure may cause irritation in eyes, skin and respiratory tract. When handling, wear appropriate protective eyewear, gloves and clothing. 
- $\quad$ Triethyl-ammonium bicarbonate $1 \mathrm{M}, \mathrm{pH} 8.5 \pm 0.1$ (TEAB) (Sigma-Aldrich, cat. no. T7408) CAUTION Handle with gloves.

- $\quad$ Ammonia solution (25\% (vol/vol)) (Merck, cat. no. 105428) CAUTION Causes severe skin burns and eye damage. May cause respiratory irritation. Handle with gloves.

- All materials described in ${ }^{43}$ for in-solution dimethyl-labelling protocol are required.

- Formaldehyde-d2 20 wt\% solution $\mathrm{CD}_{2} \mathrm{O}$ (Aldrich, cat. no. 492620-20G) CAUTION Toxic, corrosive.

- $\quad$ Formadehyde- ${ }^{13} \mathrm{C},-\mathrm{d} 2$ in $\mathrm{D}_{2} \mathrm{O},{ }^{13} \mathrm{CD}_{2} \mathrm{O}, 20$ wt\% in $\mathrm{D}_{2} \mathrm{O}$ (Isotec, cat. no.596388-1) CAUTION Toxic, corrosive.

- $\quad$ Sodium Cyanoborohydride, $\mathrm{NaBH}_{3} \mathrm{CN}$ (Fluka, cat. no. 71435-10G) CAUTION: Wear gloves.

- $\quad$ Deuterated Sodium Cyanoborohydride, $\mathrm{NaBD}_{3} \mathrm{CN}$ (Aldrich, cat. no. 190020-1G) CAUTION: Wear gloves.

- $\quad$ Acetic acid (Merck, cat no. 100063) CAUTION Flammable liquid and vapor. Causes severe skin burns and eye damage. Wear protective gloves, clothing, eye protection, and face protection.

- $\quad$ Boric acid (Merck, cat no. 100765) CAUTION May damage fertility. May damage the unborn child.

- $\quad$ Phosphoric acid (Sigma-Aldrich, cat no. 452289) CAUTION Causes severe skin burns and eye damage. Wear protective gloves, clothing, eye protection, and face protection.

- $\quad$ Sodium hydroxide (Merck, cat no. 106467) CAUTION Causes severe skin burns and eye damage. Wear protective gloves, clothing, eye protection, and face protection.

\section{EQUIPMENT}

- $\quad$ Vortex for microcentrifuge tubes MiniBeadbeater (Biospec)

- $\quad$ Calibrated plastic inoculation loop 10 ul (Daslab, cat. no 668810)

- $\quad$ Typhoon 8600 (GE Healthcare, Waukesha, WI, USA)

- Centrifugal vacuum concentrator

- Water bath sonicator (Bioruptor $\quad$ Diagenode, Sparta, NJ, USA) 
- $\quad$ Cartridge Holder kit (AB Sciex, Foster City, USA, cat. No. 4326687), which includes cartridge holder, needleport adaptor and outlet connector.

- $\quad$ Oasis ${ }^{\circledR}$ HLB Plus LP Extraction cartridges (Waters, Milford, MA, USA)

- $\quad$ Liquid chromatograph EasyLC (Thermo Fisher Scientific, Odense, Denmark) coupled to a mass spectrometer Orbitrap Velos (Thermo Fisher Scientific, Bremen, Germany) via a nano electrospray source (Thermo Fisher Scientific, San Jose, CA, USA)

- $\quad$ Reverse-phase column, 15 cm length, $100 \mu \mathrm{m}$ inner diameter, packed with $5 \mu \mathrm{m}$ C18 particles (Nikkyo Technos Co., Tokyo, Japan)

- $\quad$ MaxQuant v. 1.3.0.5

- $\quad$ Homemade Empore C18 column (3M, St. Paul, MN, USA)

- $\quad$ Strong anion exchange column (Empore anion-SR, 3M, St. Paul, MN, USA)

\section{REAGENT SETUP}

Yeast cells Yeast cells should be grown at the OD and growth media conditions desired for the experiment. Usually, a TCA extract of $S$. pombe cells at $\mathrm{OD}_{600} \sim 0.5$ yield $15 \mathrm{mg}$ of protein per litre of culture, if the protein extract is obtained with glass beads in a vortex system.

Tris- $\mathrm{HCl}$ pH $8.51 \mathrm{M}$ Dissolve $121.14 \mathrm{~g}$ of Tris base in $1 \mathrm{I}$ of $\mathrm{H}_{2} \mathrm{O}$ and adjust $\mathrm{pH} 8.5$ with $37 \%$ $\mathrm{HCl}$. It can be kept at room temperature for some time, however check $\mathrm{pH}$ and for the presence of microbial contaminations prior to use.

$100 \%$ TCA Add $107 \mathrm{ml}$ of milliQ water to $250 \mathrm{~g}$ of TCA.

$<$ CRITICAL $>$ Store all TCA solutions at $4{ }^{\circ} \mathrm{C}$ and protected from light. Under these conditions, it can be stored for at least 3 weeks.

Acetone Directly store at $-20^{\circ} \mathrm{C}$. Under these conditions, it can be stored at least for two months.

ICAT buffer $200 \mathrm{mM}$ Tris- $\mathrm{HCl} \mathrm{pH}$ 8.5, $6 \mathrm{M}$ urea, $5 \mathrm{mM}$ EDTA and $0.05 \%$ SDS.

$<$ CRITICAL $>$ Urea solutions should always be freshly prepared as they may develop significant concentrations of reactive cyanate ions. Do not allow the temperature of the solution rise above $30^{\circ} \mathrm{C}$, since urea may break down into isocyanate, which can lead to protein carbamylation. The presence of SDS and Tris in the buffers is supposed to disturb mass spec spectra and dimethyl-based amino-labelling of peptides, respectively. To avoid these problems, we 
performed desalting (steps 18-22 of ICAT labelling procedure), strong ion exchange (step 24 of ICAT labelling procedure; steps 34-37 of dimethyl labelling-fractionation) and/or reverse-phase chromatography (step 29 of the dimethyl labelling procedure) steps to eliminate SDS, Tris and urea prior to LC-MS/MS. Alternatively, both reagents can be omitted from the whole procedure with similar cysteine- and amino-labelling yielding, as shown in Supplementary Figure 2.

Alkylating buffer $100 \mathrm{mM}$ IAM in ICAT buffer. Dissolve $18.6 \mathrm{mg}$ of IAM per ml of ICAT buffer. $<$ CRITICAL > Prepare fresh, IAM solutions are unstable and light sensitive.

Reduction buffer $20 \mathrm{mM}$ TCEP in ICAT buffer. Prepare a $200 \mathrm{mM}$ stock solution of TCEP in water (28.6 mg of TCEP per $0.5 \mathrm{ml}$ of water). Add $100 \mu \mathrm{l}$ of the $200 \mathrm{mM}$ stock solution per $\mathrm{ml}$ of ICAT buffer.

$<$ CRITICAL $>$ Prepare fresh.

Heavy alkylating buffer 1 unit per ml of Cleavable ICAT Reagent Heavy in ICAT reagent solution. Prepare by dissolving the content of one vial of ICAT Reagent Heavy with $200 \mu$ of acetonitrile, according to manufacturer instructions. Once resuspended, add $800 \mu$ of ICAT buffer to reach $1 \mathrm{ml}$ of heavy alkylating buffer.

$<$ CRITICAL $>$ Prepare fresh and protect from light due to reagent instability.

Light alkylating buffer 1 unit per ml of Cleavable ICAT Reagent Light in ICAT reagent solution. Prepare by dissolving the content of one vial of ICAT Reagent Light with $200 \mu \mathrm{l}$ of acetonitrile, according to manufacturer instructions. Once resuspended, add $800 \mu \mathrm{l}$ of ICAT buffer to reach $1 \mathrm{ml}$ of light alkylating buffer.

$<$ CRITICAL $>$ Prepare fresh and protect from light due to reagent instability.

Ammonia solution $1 \%$ Dilute $3 \mu \mathrm{l}$ of $25 \%$ ammonia solution in $72 \mu \mathrm{l}$ of water.

TEAB $25 \mathrm{mM} 25 \mu \mathrm{l}$ of TEAB $1 \mathrm{M}$ in $1 \mathrm{ml}$ of water.

$<$ CRITICAL $>$ Prepare fresh.

$\mathrm{NaOH} 5 \mathrm{M}$ Disolve $200 \mathrm{~g}$ of $\mathrm{NaOH}$ in 1 liter of water. It can be stored for long time if air contact is minimized.

Britton \& Robinson buffer (pH 2) Add $71.5 \mu$ of acetic acid, $74.2 \mathrm{mg}$ of boric acid, and $82 \mu \mathrm{l}$ of phosphoric acid to $60 \mathrm{ml}$ of water. This allows a buffer composition of $20 \mathrm{mM}$ acetic acid, 20 $\mathrm{mM}$ boric acid and $20 \mathrm{mM}$ phosphoric acid. Prepare fresh.

Britton \& Robinson buffer $(\mathrm{pH} 2)$ is treated with $\mathrm{NaOH} 5 \mathrm{M}$ to obtain solutions at different $\mathrm{pH}$ : 
- $\quad$ pH 3: add $150 \mu$ of $5 \mathrm{M} \mathrm{NaOH}$ to $60 \mathrm{ml}$ of Britton and Robinson buffer. Prepare fresh and keep $10 \mathrm{ml}$ of this solution at $4^{\circ} \mathrm{C}$ until it is needed.

- $\quad$ pH 4: add $283 \mu \mathrm{l}$ of $5 \mathrm{M} \mathrm{NaOH}$ to $50 \mathrm{ml}$ of Britton and Robinson buffer $\mathrm{pH}$ 3. Prepare fresh and keep $10 \mathrm{ml}$ of this solution at $4{ }^{\circ} \mathrm{C}$ until it is needed.

- pH 5: add $65 \mu \mathrm{l}$ of $5 \mathrm{M} \mathrm{NaOH}$ to $40 \mathrm{ml}$ of Britton and Robinson buffer $\mathrm{pH}$ 4. Prepare fresh and keep $10 \mathrm{ml}$ of this solution at $4{ }^{\circ} \mathrm{C}$ until it is needed.

- $\quad$ pH 6: add $35 \mu \mathrm{l}$ of $5 \mathrm{M} \mathrm{NaOH}$ to $30 \mathrm{ml}$ of Britton and Robinson buffer $\mathrm{pH}$ 5. Prepare fresh and keep $10 \mathrm{ml}$ of this solution at $4{ }^{\circ} \mathrm{C}$ until it is needed.

- pH 8: add $25 \mu \mathrm{l}$ of $5 \mathrm{M} \mathrm{NaOH}$ to $20 \mathrm{ml}$ of Britton and Robinson buffer $\mathrm{pH}$ 6. Prepare fresh and keep $10 \mathrm{ml}$ of this solution at $4{ }^{\circ} \mathrm{C}$ until it is needed.

- $\quad$ pH 11: add $35 \mu$ l of $5 \mathrm{M} \mathrm{NaOH}$ to $10 \mathrm{ml}$ of Britton and Robinson buffer $\mathrm{pH}$ 8. Prepare fresh and keep this solution at $4{ }^{\circ} \mathrm{C}$ until it is needed.

\section{EQUIPMENT SETUP}

In principle any LC-MS/MS setup can be used for this analysis, but because of anticipated low sample amounts nanoflow liquid chromatography (LC; $100-500 \mathrm{nl} / \mathrm{min}$ ) is recommended due to its higher sensitivity.

\section{Liquid chromatography}

With regard to liquid chromatography, it is important to distinguish the two types of samples to be analysed. The ICAT-labelled enriched samples are expected to be of lower complexity and therefore do not require extended long gradients. The dimethyl-labelled sample complexity is high and will benefit from longer $(3 \mathrm{~h})$ gradients and/or orthogonal to reversed phase prefractionation prior to LC-MS/MS analysis. Since the quantification of both ICAT- and dimethyllabelled samples is based on MS rather than MS/MS spectra, the latter being the case for isobaric tags exemplified by iTRAQ and TMT, it is important that enough MS spectra are generated per peptide to obtain sound quantification. Applied gradients should therefore not be too steep (suggestion for gradients and MS parameters are available in Supplementary Data 1 and 2). We have not observed large retention time shifts between the same peptide modified with ICAT and modified with carbamidomethyl (Supplementary Data 3) and the resolving 
gradients final percent of organic (buffer B) is therefore not different between the two types of samples to be analysed.

\section{Mass spectrometers}

As for most stable isotope based quantification experiments, using a mass spectrometer capable of measuring precursor masses with high resolution and high mass accuracy is beneficial. For this protocol we recommend an Orbitrap mass spectrometer (ThermoScientific), solely because the data format from this type of instruments feeds well into MaxQuant v. 1.3.0.5, that in addition to peptides with a single ICAT modified cysteine, also allows for an automated quantification of peptides with multiple cysteines modified differently (Supplementary Data 4-6). Alternative software includes ProteomeDiscoverer v. 1.4 (ThermoScientific), thought ICAT quantification by this platform only works for peptides where all cysteines are modified by the ICAT reagent. Examples of LC gradients, settings for a QExactive mass spectrometer (Thermo) and important steps for the data analysis are described in Supplementary Data section. 


\section{PROCEDURE}

This strategy is designed to relatively compare two redox proteomes.

\section{Freezing thiol-redox status $<5$ min $>$}

1| Freeze the thiol-redox status by adding chilled 100\% TCA up to a final concentration of $10 \%$ directly to $150-\mathrm{ml}$ cultures at an $\mathrm{OD}_{600} \sim 0.5\left(15 \times 10^{8}\right.$ cells $)$. This amount of cells will yield approximately $2 \mathrm{mg}$ of total protein extracts for ICAT labelling (step 11). Allow acidification for a minute before harvesting.

$<$ CRITICAL $>$ TCA has to be added without altering the growing conditions of the culture (i.e. if the culture is growing in a flask with shaking, do not stop shaking).

\section{? TROUBLESHOOTING}

\section{Preparation of cell lysates $<1$ hour $>$}

$<$ CRITICAL $>$ During lysis, cells and lysates should be kept at $4{ }^{\circ} \mathrm{C}$ at all times.

2| Harvest cells by centrifugation at $2,000 \mathrm{~g}$ for $3 \mathrm{~min}$ at $4{ }^{\circ} \mathrm{C}$. Collect cells into a $1.5 \mathrm{ml}$ microcentrifuge tube with $1 \mathrm{ml}$ of chilled $20 \%$ TCA. Centrifuge at $20,000 \mathrm{~g}$ for 30 seconds and take out supernatants.

$<$ CRITICAL $>$ To allow good performance in all following steps, the maximum amount of cells to be collected into a $1.5 \mathrm{ml}$ centrifuge tube is the corresponding to a $50 \mathrm{ml}$ of culture at $\mathrm{OD}_{600} \sim 0.5\left(5 \times 10^{8}\right.$ cells $)$.

PAUSE POINT Pellets can be stored at $-80^{\circ} \mathrm{C}$ at least for 2 weeks.

3 | Monitoring step (optional): we propose to check reversible thiol oxidation by 1D electrophoresis previously to follow with the whole protocol. This can be done with the amount of pellet equivalent to $10 \mathrm{ml}$ of culture. $\ln ^{37}$ there is a full description of the recommended protocol. The rest of the sample can remain at $-80^{\circ} \mathrm{C}$ until further processed. To generate control samples with severe thiol oxidation, some treatments which we usually apply to yeast cells are $5 \mathrm{mM} \mathrm{H}_{2} \mathrm{O}_{2}$ or $1 \mathrm{mM}$ diamide for 1-5 min, although these control treatments may change depending on the cell type.

4| Resuspend pellets in $250 \mu$ of $12.5 \%$ TCA. Fill with glass beads up to $85-90 \%$ of the volume to allow proper disruption.

5| To disrupt cells, vortex at maximum speed for $5 \mathrm{~min}$ in a vortex for microcentrifuge tubes. 
$<$ CRITICAL $>$ To avoid overheating of the lysates, keep the vortex in a cold chamber at $4^{\circ} \mathrm{C}$.

6| Pierce two holes, one in the bottom and the other in the top of each $1.5-\mathrm{ml}$ microcentrifuge tube, with a flame-heated needle $(0.6 \times 25 \mathrm{~mm})$, and place each tube on the top of another $1.5-\mathrm{ml}$ tube. Centrifuge to separate the lysate from the beads at $850 \mathrm{~g}$ for $30 \mathrm{sec}$ at $4{ }^{\circ} \mathrm{C}$.

7| Centrifuge the cell lysates at $20,000 \mathrm{~g}$ for $20 \mathrm{~min}$ at $4{ }^{\circ} \mathrm{C}$.

8| Take out supernatants, and wash pellets with $1 \mathrm{ml}$ of chilled acetone $\left(-20^{\circ} \mathrm{C}\right)$, with the help of the blunt side of a plastic inoculation loop. Centrifuge at $20,000 \mathrm{~g}$ for $5 \mathrm{~min}$ at 4 ${ }^{\circ} \mathrm{C}$.

9| Take out supernatants, and repeat the previous step.

10 Take out supernatants and dry pellets with the help of a vacuum concentrator, by centrifuging $2 \mathrm{~min}$ at $37^{\circ} \mathrm{C}$. Alternatively, pellets can be dried by placing them for $\sim 8$ min in an oven pre-heated at $55^{\circ} \mathrm{C}$.

\section{Alkylation of reduced cysteines $<90 \mathrm{~min}>$}

11 Alkylate cysteines by resuspending each dried pellet in $500 \mu \mathrm{l}$ of alkylating buffer, with the help of the blunt side of a plastic inoculation loop. Incubate at $25^{\circ} \mathrm{C}$ for 15 min in the dark and with shaking.

\section{? TROUBLESHOOTING}

12 Centrifuge at $20,000 \mathrm{~g}$ for $5 \mathrm{~min}$ at room temperature $\left(20-25^{\circ} \mathrm{C}\right)$ to remove aggregates. Collect each supernatant and transfer it to a new $1.5-\mathrm{ml}$ microcentrifuge tube. To precipitate proteins and remove excess IAM, add $500 \mu$ of chilled $20 \%$ TCA to each supernatant, mix and place at $-20^{\circ} \mathrm{C}$ for $10 \mathrm{~min}$. Centrifuge at $20,000 \mathrm{~g}$ for 10 min, and remove the supernatants.

14 Wash each pellet with $1 \mathrm{ml}$ of cold acetone, as in step 8. Centrifuge at 20,000 g for $5 \min$ at $4^{\circ} \mathrm{C}$.

15 Remove supernatants and repeat the previous step.

16 Remove supernatants and dry pellets with a vacuum concentrator, as in step 10. 


\section{Reduction of reversibly oxidized cysteines $<60 \mathrm{~min}>$}

17 Reduce the reversibly oxidized cysteines by resuspending each pellet in $300 \mu \mathrm{l}$ of reduction buffer with the help of the blunt side of a plastic inoculation loop. 30 seconds of sonication at the maximum power in a water bath sonicator may help to resuspend pellets. Incubate for $30 \mathrm{~min}$ at $30^{\circ} \mathrm{C}$.

18 At this time, pool all aliquots belonging to the same condition. Determine protein concentration by Bradford assay.

19 Withdraw $100 \mu \mathrm{g}$ of each condition for dimethyl labelling (this amount of protein is contained in approximately $16 \mu \mathrm{l}$ of volume) (see below, dimethyl labelling section). <PAUSE POINT> This withdrawn sample can be stored at $-20^{\circ} \mathrm{C}$ for at least one week.

20 For each condition, precipitate $\sim 2 \mathrm{mg}$ of protein by adding an equivalent volume of chilled $20 \% \mathrm{TCA}$, mix and place at $-20^{\circ} \mathrm{C}$ for $10 \mathrm{~min}$. Centrifuge at $20,000 \mathrm{~g}$ for 10 min, and take out the supernatants.

$<$ CRITICAL $>$ Precipitate exactly the same amount of protein for each condition.

? TROUBLESHOOTING

21 Wash each pellet with $1 \mathrm{ml}$ of cold acetone, as in step 1-(vi). Centrifuge at $20,000 \mathrm{~g}$ for $5 \mathrm{~min}$ at $4{ }^{\circ} \mathrm{C}$.

22 Take out supernatants and repeat the previous step.

23 Take out supernatants and dry pellets with the help of a vacuum concentrator, as in step 1-(viii).

ICAT labelling of reversibly oxidized cysteines $<140 \mathrm{~min}>$

24 I Resuspend the pellet belonging to one condition with $1 \mathrm{ml}$ of heavy alkylating buffer, and the pellet belonging to the other condition with $1 \mathrm{ml}$ of light alkylating buffer with the help of the blunt side of a plastic inoculation loop. 30 seconds of sonication at the maximum power in a water bath sonicator may help to resuspend pellets. Incubate for 2 hours at $37^{\circ} \mathrm{C}$ in the dark and with shaking.

? TROUBLESHOOTING 
excess over ICAT reagent). Allow the reaction to take place by incubation at room temperature for $5 \mathrm{~min}$.

26 Monitoring step (optional): we recommend to check ICAT labelling performance by electrophoretically separating a small amount of protein from each condition $(2.5 \mu \mathrm{g}$ of protein) in reducing SDS/PAGE, prior to trypsin digestion and MS analysis. After immunoblotting, relative differences on ICAT-labelled cysteines between samples can be visualized by detection with standard anti-biotin or streptavidin-conjugated antibodies.

Trypsin digestion $<16$ hours $>$

27 Pool light and heavy reactions in a $15 \mathrm{ml}$ tube. Dilute them by adding $10 \mathrm{ml}$ of $10 \mathrm{mM} \mathrm{CaCl}_{2}$ to reduce the urea concentration to $1 \mathrm{M}$. Add $100 \mu \mathrm{g}$ of TPCK-treated trypsin (1:40 ratio) and let the digestion to take place for 16 hours at $37^{\circ} \mathrm{C}$ with mild agitation and light protected.

28 Monitoring step (optional): Appropriate trypsin digestion can be followed by processing a tiny fraction of the sample by mass spectrometry and check peptide missed cleavages and ion charges.

? TROUBLESHOOTING

Peptide desalting $<30$ min $>$

29 Peptides must be desalted to remove salts and urea from the digestion buffer. We use Oasis ${ }^{\circledR}$ HLB Plus LP Extraction cartridges which are appropriate for peptide amounts $>10 \mu \mathrm{g}$.

30 Wash and condition the cartridge with $5 \mathrm{ml}$ of $100 \% \mathrm{ACN}$.

31 Equilibrate with $5 \mathrm{ml}$ of $5 \%$ formic acid.

32 Acidify the sample to $\mathrm{pH} 2-3$ with formic acid and load it into the cartridge.

33 Wash with $5 \mathrm{ml}$ of $5 \%$ formic acid.

34 Elute with $5 \mathrm{ml}$ of $70 \% \mathrm{ACN} / 5 \%$ formic acid. Evaporate the sample to dryness with a vacuum concentrator for $1.5 \mathrm{ml}$ microcentrifuge tubes (4-5 hours).

35 Perform cation exchange chromatography, affinity purification and biotin cleavage exactly according to ICAT kit manufacturer instructions. $<7$ hours $>$ 

and further process following manufacturer instructions up to finishing the section of cleaving the ICAT Reagent-Labelled peptides. At this point, the sample is a dry pellet ready to be separated and analyzed by LC-MS/MS.

\section{LC-MS/MS of ICAT labelled peptides <1 day>}

37 Resuspend dry pellet in $15 \mu \mathrm{l}$ of loading solvent and inject the sample onto the LC-MS/MS system. Analyse samples by LC-MS/MS in 3 runs of $5 \mu$ each. See EQUIPMENT SETUP for details.

\section{Dimethyl labelling $<1$ day $>$}

$<$ CRITICAL $>\quad$ In step 10 of the procedure, $100 \mu \mathrm{g}$ of total protein extracts for each condition (in our case, $100 \mu \mathrm{g}$ of protein were reached in a volume of $16 \mu \mathrm{l}$ ) were withdrawn for dimethyl labelling. We followed the in-solution protocol described in Boersema et al. ${ }^{43}$, with some modifications meant to allow subsequent sample fractionation to reach higher proteome coverage after LC-MS/MS.

38 Reduce the samples with $30 \mu \mathrm{l}$ of $10 \mathrm{mM} \mathrm{DTT}$ at $37^{\circ} \mathrm{C}$ for 1 hour.

39 I Alkylate the samples with $30 \mu \mathrm{l}$ of $20 \mathrm{mM}$ IAM in $200 \mathrm{mM}$ TEAB for $30 \mathrm{~min}$ at room temperature in the dark.

40 Dilute sample to $<1 \mathrm{M}$ urea by adding $50 \mu \mathrm{l}$ of $200 \mathrm{mM}$ TEAB and digest with 2 $\mu g$ of trypsin (ratio 1:50) during 10 hours. Stop digestion by acidification with $18 \mu$ of formic acid.

41 After protein digestion, desalt $25 \mu \mathrm{g}(36 \mu \mathrm{l})$ of the sample with two disks of Empore C18. Upon cleaning, dry the sample by vacuum centrifugation.

42 Reconstitute the digested samples in $100 \mu \mathrm{l} 25 \mathrm{mM}$ TEAB. $<$ CRITICAL $>25 \mathrm{mM}$ TEAB is used instead of $100 \mathrm{mM} \mathrm{TEAB}{ }^{43}$ when performing strong anion exchange after labelling. Too high salt percentage interferes with peptide sticking to the anion exchange material.

43 Continue the protocol as described in ${ }^{43}$, In-solution stable isotope dimethyl labeling, steps (ii) to (vii).

? TROUBLESHOOTING 
At this stage, each sample is mixed with the dimethyl labelling reagents in a final volume of $124 \mu \mathrm{l}$. Add $8 \mu \mathrm{l}$ of $1 \%$ (vol/vol) ammonia solution to each sample. $<$ CRITICAL $>$ The sample is not acidified as in ${ }^{43}$ but further ammonia solution is added, to facilitate the anion exchange fractionation prior to LC-MS/MS (see below).

45 Mix the two differentially labelled samples.

Fractionation of dimethyl labelled peptides by strong anion exchange $<2$ hours $>$ After mixing the samples and prior to LC-MS/MS analysis, dimethyl labelled peptides were separated into six $\mathrm{pH}$ fractions $(11,8,6,5,4$ and 3$)$ following the protocol described in ${ }^{58}$. $<$ CRITICAL $>$ Fractionation by strong anion exchange is recommended to enhance proteome coverage after LC-MS/MS analysis, but is also required for efficient removal of SDS.

Build a solid phase column by stamping out an anion exchange disk using a blunt syringe needle. Place one membrane for each 5-15 $\mu \mathrm{g}$ of sample into a $200 \mu \mathrm{l}$ plastic tip. For column equilibration use $100 \mu \mathrm{l}$ of Britton \& Robinson buffer pH 11.

48 Add $9 \mu \mathrm{l}$ of $\mathrm{NaOH} 0.5 \mathrm{M}$ to the dimethyl labelled peptides.

49 Load the dimethyl labelled peptides (collect the flow-through) and elute fractions with $25 \mu$ l each of Britton \& Robinson buffer solutions of $\mathrm{pH} 8,6,5,4$, and 3 , respectively.

50 I Acidify all collected fractions, including the flow-through, by adding $10 \mu \mathrm{l}$ of formic acid to the flow-through fraction and $2.5 \mu$ of formic acid to eluted fractions at $\mathrm{pH}$ $8,6,5$, and 4 , and desalt through homemade C18 columns prior to analysis by LCMS/MS.

\section{LC-MS/MS of dimethyl labelled peptides <1day>}

51 Resuspend dry pellet in $15 \mu$ l of loading solvent and inject the sample onto the LC-MS/MS system. Analyse samples by LC-MS/MS in 3 runs of $5 \mu$ each. See EQUIPMENT SETUP for details.

Data analysis $<1$ day $>$ 
52 Analyse the data obtained using the information in Box 1 as a guide. Analysis of the dimethyl labelled peptides is described in detail in the Nature Protocol by Boersema et al. (ref. 41). 


\section{Box 1 Data Analysis}

This protocol includes two types of relative quantification: a protein centric comparison of the two samples of dimethyl labelled peptides, and a peptide centric comparison of ICAT labelled peptides. Modifications used for the tandem MS search are listed in Supplementary Data 7. The protein centric comparison of the two samples is described in great detail by Boersema et al ${ }^{43}$ and most quantification software's will handle this analysis well. For the peptide centric quantification analysis it is preferred to use software capable of quantifying peptides with multiple cysteine residues differing in labelling, e.g. one cysteine is carbamidomethylated while another is ICAT labelled within the same peptide. Some quantification softwares (e.g. ProteomeDiscoverer v. 1.4. Thermo) will disqualify such peptides as 'incomplete labelled' and no quantitative measures will be available for this group of peptides. MaxQuant v. 1.3.0.5 (http://maxquant.org) ${ }^{57}$ can handle this group of differential labelled cysteines. For the dataset shown here, $\sim 10 \%$ of all peptides contained two or more cysteines. In addition, for the MaxQuant platform, it is possible to define multiple groups of search and quantification parameters making it possible to combine the protein centric and the peptide centric data in one analysis. Benefits to this strategy include i) consistent gene symbols and protein names between the protein centric and the peptide centric correlations, and ii) the combined data set is used to calculate false discovery rate. Limitation to this strategy: currently the MaxQuant v. 1.3.0.5 software is limited to the RAW data format (ThermoScientific). Alternative software strategy that allows to quantitate peptides containing multiple and differential labelled cysteines is to combine MSQuant (http://msquant.alwaysdata.net/) ${ }^{59} 60$ with MASCOT (Matrixscience), as previously described ${ }^{37}$. The objective of this procedure is not to be a manual for MaxQuant v. 1.3.0.5 but important parameters are listed below, and the Supplementary Data section contains descriptive figures:

1) Load .RAW files from measurements of the ICAT as well as dimethyl samples.

2) Define .RAW files appropriately. Use different 'Parameter groups' for the ICAT and the dimethyl data files (Supplementary Data 8 and 9). 
3) Create an experimental design ('Exp. Design'). Once created this file (experimentalDesignTemplate.txt) can be found in folder 'Combined' (found in the folder containing the RAW data). - Use a text editor to describe the experiment and save this file (Supplementary Data 8, ii).

4) In the tab 'Group specific parameters' define the search and quantification parameters for the dimethyl experiment ('Group 1') and the ICAT experiment ('Group 2'). For both experiments it is important that carbamylation of cysteines is chosen as a variable modification (Supplementary Data 8, iii).

5) In the 'MS/MS and sequences' tab, it is important that carbamylation of cysteines is not chosen as a fixed modification (Supplementary Data 8, iv).

6) In the tab 'Quantification \& identification' it is important to include carbamylation of cysteines to the modification box 'Use only unmodified peptides and...' under 'Protein quantification'.

7) Select the 'experimentalDesignTemplate.txt' file describing the experimental relation between the generated .RAW files (Supplementary Data 8, v).

8) The search is started by clicking 'Start'.

9) Upon completion of the search and quantification, results are found in 'combinedltxt'. The ICAT results should be retrieved from the peptide centric files: 'peptides.txt' and 'evidense.txt' of which the latter includes more granular information. The protein centric dimethyl based quantification can be retrieved from the file 'proteinGroups.txt'. Examples of comparing the dimethyl and ICAT results are shown in Supplementary Data 9. A scatter plot comparison of two experiments is shown in Supplementary Data 10.

10) When possible: For specific oxidized cysteine residues compare the measured ICAT ratios to the protein ratios obtained in the dimethyl part of the experiment. Where the ICAT ratios are cysteine specific, the dimethyl ratios are protein specific, and this comparison therefore allows differentiating if a measured change in cysteine oxidation level is accompanied with changes in protein amount. 


\section{ANTICIPATED RESULTS}

To demonstrate the performance of the proposed ICAT-based biotin switch assay combined with dimethyl labelling, we exemplify here how this methodology was successfully used to compare the oxidized proteome of untreated wild-type S. pombe cells and three environmental or genetic conditions: extracts from $0.2 \mathrm{mM} \mathrm{H}_{2} \mathrm{O}_{2}$ treated wild-type cells or from cells lacking Trx1 (the main cytoplasmatic thioredoxin in S. pombe) or Trr1 (the only thioredoxin reductase of fission yeast). Our aim was to interrogate thiol homeostasis by providing an extracellular source of oxidants and by genetically compromising the thioredoxin system. As indicated in the Experimental Design section, and prior to perform this ICAT-based proteomic methodology to compare two Cys-oxidized proteomes, we strongly encourage researchers to perform as a pilot experiment the fluorescent labelling of oxidized thiols in TCA extracts followed by fluorescent scanning of 1D gels, as previously published ${ }^{37}$. As shown in Figure $\mathbf{2 a}$ using this strategy, all three biological conditions triggered general thiol oxidation but to different extents, with cells lacking Trr1 clearly displaying increased thiol oxidation.

Following the procedure described above and summarised in Figure 1, extracts from wild-type untreated cells (condition 1) are compared with extracts from another environmental biological sample (condition 2). In this case, condition 2 was either an environmental (treatment of wild-type cells with mild concentrations of $\mathrm{H}_{2} \mathrm{O}_{2}$ ), or a genetic intervention (cells lacking Trx1 or Trr1).

For the identification of ICAT labelled peptides in the experiment corresponding to Figure 2, 2 biological replicates, with 2 to 3 technical replicates each, were performed for all four tested conditions (extracts from wild-type cells, from wild-type cells treated with $\mathrm{H}_{2} \mathrm{O}_{2}$, and from $\Delta$ trx 1 and $\Delta t r r 1$ cells). Technical replicates increased peptide identifications $\sim 50 \%$, resulting in an average of 500 ICAT labelled peptides detected for any studied condition. In terms of sensitivity, this approach allows the identification and quantification of proteins expressed at low levels, exemplified by the S. pombe transcription factor Pap1 (Supplementary Tables 1 to 3$)$.

One biological replicate of each ICAT pair was subjected to protein quantification by dimethyl labelling. Three technical replicates and sample fractionation into six $\mathrm{pH}$ fractions prior 
to analysis by LC-MS/MS were performed for this approach. This resulted in the identification and quantification of more than one peptide for $>75 \%$ of the dimethyl labelled proteins for any condition. An average dimethyl ratio was calculated for each protein by using the individual ratios of all peptides belonging to the same protein. 72 to $78 \%$ of the ICAT labelled peptides enriched in the affinity purification step belonged to proteins whose relative concentrations were determined by dimethyl labelling. If we look at the whole set of dimethyl labelled proteins, we were able to quantify the $19-30 \%$ of the fission yeast proteome, depending on the studied condition. A larger proteome coverage can easily be achieved by increasing the number of fractions per sample prior to LC-MS/MS analysis ${ }^{58}$

To correct possible bias due to differential protein loading between ICAT pairs, the overall median value of all dimethyl ratios for a specific condition was used to normalize both individual ICAT and dimethyl ratios obtained for the same condition. As an example, in Figure $\mathbf{2 b}$ is represented the distribution of the ICAT ratios and dimethyl ratios for one experimental condition before (left panel) and after (right panel) data normalization.

Only peptides present in at least 2 biological replicates were used to finally describe those proteins with increased levels of reversible oxidized thiols in each experimental setting, when compared with the wild-type untreated condition. In Figure $\mathbf{2 c}$ there is an example of the overlapping areas of the ICAT labelled peptides between the two biological replicates for extracts from cells lacking Trx1 vs extracts from wild-type untreated cells. Taking into account those peptides with a ratio of cysteine oxidation versus protein levels over 1.5 -fold, we obtained percentages of reversible oxidation that goes up to $8 \%$ upon $\mathrm{H}_{2} \mathrm{O}_{2}$ treatment, up to $30 \%$ in cells lacking Trr1 and close to $1.3 \%$ in the absence of Trx1 (Fig. 2c). These proteomic-based peptide oxidation percentages show very good agreement with those levels of reversible oxidized proteins as determined by 1D electrophoresis (Fig. 2a)., When a strain or an environmental condition has low levels of reversible oxidized thiols, only those truly oxidized appear with high ICAT ratios in the different biological replicates when compared with a wildtype strain or situation (this would be the case of the $\Delta \operatorname{trx} 1$ strain when compared with a wildtype strain); however, the technique is strong enough as to detect a massive number of peptides with high ICAT ratios when the strain or environmental condition generates high levels of reversible oxidized thiols [that is the case for strains lacking thioredoxin reductase, for which 
up to 56 Cys-containing peptides (out of $190 ; 30 \%$ ) were identified as being more oxidized that in wild-type extracts; Fig. 2d]. The full list of peptides identified as reversibly-oxidized in our biological samples is provided in Supplementary Tables 1 to 3. Our proteomic study allowed us to conclude that (i) $\mathrm{H}_{2} \mathrm{O}_{2}$ is able to reversibly oxidize most peroxide scavengers and several sensitive cysteine residues in proteins; (ii) in the absence of thioredoxin only specific substrates are over-oxidized, but not the general thiol proteome; (iii) the absence of thioredoxin reductase inverts the redox function of thioredoxin, a natural electron donor, and general thiol oxidation occurs. 
Table 2 | Troubleshooting table

\begin{tabular}{|c|c|c|c|}
\hline Steps & Problem & Possible reason & Solution \\
\hline Step 1 & $\begin{array}{l}\text { Unspecific cysteine } \\
\text { oxidations when } \\
\text { sample handling } \\
\text { along the procedure }\end{array}$ & $\begin{array}{l}\text { Cysteine reactivity was } \\
\text { not properly blocked } \\
\text { prior to thiol alkylation } \\
\text { with IAM }\end{array}$ & $\begin{array}{l}\text { Make sure that TCA is added prior to } \\
\text { cell lysis. Alternatively, but with less } \\
\text { efficiency, other acids or permeable } \\
\text { alkylating agents can be used to block } \\
\text { the in vivo reactivity of cysteines }{ }^{45}\end{array}$ \\
\hline $\begin{array}{l}\text { Step 1, } \\
24\end{array}$ & $\begin{array}{l}\text { The procedure is too } \\
\text { expensive if I have to } \\
\text { label with ICAT } \\
\text { reagents up to } 2 \mathrm{mg} \\
\text { of total protein (step } \\
\text { 24) }\end{array}$ & $\begin{array}{l}\text { Heavy and Light } \\
\text { Cleavable ICAT } \\
\text { reagents are designed, } \\
\text { according to the } \\
\text { manufacturer, to label } \\
\text { only up to } 100 \mu \mathrm{g} \text { of } \\
\text { protein, and our starting } \\
\text { material (step 24) is } 2 \\
\text { mg of protein. }\end{array}$ & $\begin{array}{l}\text { In a typical protein extract, less than } \\
5 \% \text { of cysteines are oxidized in a } \\
\text { reversible form }{ }^{37} \text {. At step } 24 \text {, all } \\
\text { original thiols are already alkylated } \\
\text { with the inexpensive IAM. A single } \\
\text { vial of Heavy or Light Cleavable ICAT } \\
\text { reagent suffices to label all reversible } \\
\text { oxidized cysteines contained in } 2 \mathrm{mg} \\
\text { of protein extract (approximately } 100 \\
\mu \text { g of ICAT-reacting material) }\end{array}$ \\
\hline
\end{tabular}

$\begin{array}{lll}\text { Steps } & \text { Incomplete IAM } & \text { The } \mathrm{pH} \text { after pellet } \\ 11,24 & \text { and/or ICAT } & \text { resuspension is not } \\ & \text { alkylation } & \sim 8.5\end{array}$

Step 24 Failed ICAT labelling Reagent has degraded

ICAT reagents label other than cysteine residues

Unspecific reactivity of the ICAT reagents

Inappropriate dilution of the sample prior to digestion

Inappropriate dilution buffer

Step 43

Incomplete dimethyl labelling

Data analysis
Incomplete protease digestion
Reagent has degraded

Use of primary amines (i.e. Tris) in the labelling buffer

The sample contains polymers such as detergents

\author{
Polymers are visible \\ chromatogram
}

Poor quantification data
Not all variable modifications are included in the search
Use strong buffering conditions, such as the ones suggested (200 mM Tris $\mathrm{pH}$ 8.5). Check pH.

Check storage conditions. Check by 1D electrophoresis ICAT labelling before continue with the procedure

It is worth using IAM and not other alkylating agents such as NEM as the the first alkylating step (step 11). In this way, the IAM-based ICAT reagents will only specifically label cysteine residues (step 24)

Since light and heavy alkylating buffers both contain $6 \mathrm{M}$ urea, make sure samples are diluted to $<1 \mathrm{M}$ urea prior to digestion

If the used trypsin belongs to the ICAT kit, make sure that dilution is made in $10 \mathrm{mM} \mathrm{CaCl}_{2}$

Check storage conditions

Do not omit reverse-phase chromatography (step 41), and/or change to TEAB buffer (Supplementary Fig. 2)

Avoid the use of polymer-based compounds such as detergents. Perform strong ion exchange chromatography to clean samples prior to LC-MS/MS

Carbamidomethylation (IAM) and ICAT are variable modifications in cysteines. IAM is required for an 
algorithms.

There are not quantified peptides with multiple differentially labelled cysteines

The average ratio of all dimethyl quantified peptides is not 1

The protein coverage obtained from the dimethyl labelling procedure is low appropriate efficient labelling of reduced cysteines but the use of excess IAM can result in modification of other amino acids such as methionines. Peptides with a IAM modified methionine often exhibit a characteristic neutral loss of 2(methylthio)acetamide (C3H7NOS, $105.0248 \mathrm{Da})^{61,62}$. Dimethyl labels $\mathrm{N}$-termini and lysine residues.

The software used for quantification is not

Use a combination of MSQuant with MASCOT, or alternatively use

MaxQuant v. 1.3.0.5 or

ProteomeDiscoverer

Samples were not labelled in a 1:1 ratio

Normalize the data to correct for the difference in the amount of sample input

Sample was not properly fractionated
Sample fractionation as described in step 37 may increase the number of quantified proteins by 4 fold ${ }^{58}$ 


\section{TIMING}

ICAT procedure: 4 days

Dimethyl-labelling: 3 days (can be performed in parallel to ICAT procedure) 


\section{ACKNOWLEDGMENTS}

We acknowledge the CRG-UPF proteomic facility, where the LC-MS/MS experiments were performed. This work was supported by the Spanish Ministry of Science and Innovation (BFU2009-06933 and BFU2012-32045), PLAN E and FEDER, by the Spanish program Consolider-Ingenio 2010 Grant CSD 2007-0020, and by SGR2009-195 from Generalitat de Catalunya (Spain) to E.H. E. H. and J.A. are recipients of ICREA Academia Awards (Generalitat de Catalunya).

\section{AUTHOR CONTRIBUTIONS}

S.G.-S. and S.B. developed the protocol and conducted the experiments. S.G.-S., H.M. and S.B. interpreted the data. H.M. performed the LC-MS/MS experiments, and manuscript editing. A.D. performed some control experiments. J.A. provided intellectual expertise. S.G.-S. drafted the manuscript. E.H. was responsible for project supervision, data interpretation, manuscript editing and providing grant support.

\section{COMPETING FINANCIAL INTERESTS}

The authors declare no competing financial interests. 


\section{REFERENCES}

1. Gilbert, H. F. Molecular and cellular aspects of thiol-disulfide exchange. Adv Enzymol Relat Areas Mol Biol 63, 69-172 (1990).

2. Ghezzi, P. Protein glutathionylation in health and disease. Biochim Biophys Acta 1830, 3165-72 (2013).

3. Auclair, J. R. et al. Structural Consequences of Cysteinylation of Cu/Zn-Superoxide Dismutase. Biochemistry 52, 6145-6150 (2013).

4. Hochgrafe, F. et al. S-cysteinylation is a general mechanism for thiol protection of Bacillus subtilis proteins after oxidative stress. J Biol Chem 282, 25981-5 (2007).

5. Salmeen, A. et al. Redox regulation of protein tyrosine phosphatase 1B involves a sulphenyl-amide intermediate. Nature 423, 769-73 (2003).

6. van Montfort, R. L., Congreve, M., Tisi, D., Carr, R. \& Jhoti, H. Oxidation state of the activesite cysteine in protein tyrosine phosphatase 1B. Nature 423, 773-7 (2003).

7. Winterbourn, C. C. \& Hampton, M. B. Thiol chemistry and specificity in redox signaling. Free Radic Biol Med 45, 549-61 (2008).

8. D'Autreaux, B. \& Toledano, M. B. ROS as signalling molecules: mechanisms that generate specificity in ROS homeostasis. Nat Rev Mol Cell Biol 8, 813-24 (2007).

9. Hess, D. T., Matsumoto, A., Kim, S. O., Marshall, H. E. \& Stamler, J. S. Protein Snitrosylation: purview and parameters. Nat Rev Mol Cell Biol 6, 150-66 (2005).

10. Meyer, Y., Buchanan, B. B., Vignols, F. \& Reichheld, J. P. Thioredoxins and glutaredoxins: unifying elements in redox biology. Annu Rev Genet 43, 335-67 (2009).

11. Vlamis-Gardikas, A. The multiple functions of the thiol-based electron flow pathways of Escherichia coli: Eternal concepts revisited. Biochim Biophys Acta 1780, 1170-200 (2008).

12. Sengupta, R. \& Holmgren, A. Thioredoxin and thioredoxin reductase in relation to reversible S-nitrosylation. Antioxid Redox Signal 18, 259-69 (2013).

13. Benhar, M., Forrester, M. T. \& Stamler, J. S. Protein denitrosylation: enzymatic mechanisms and cellular functions. Nat Rev Mol Cell Biol 10, 721-32 (2009).

14. Poole, L. B. \& Nelson, K. J. Discovering mechanisms of signaling-mediated cysteine oxidation. Curr Opin Chem Biol 12, 18-24 (2008). 
15. Anand, P. \& Stamler, J. S. Enzymatic mechanisms regulating protein S-nitrosylation: implications in health and disease. J Mol Med (Berl) 90, 233-44 (2012).

16. Sha, Y. \& Marshall, H. E. S-nitrosylation in the regulation of gene transcription. Biochim Biophys Acta 1820, 701-11 (2012).

17. Marozkina, N. V. \& Gaston, B. S-Nitrosylation signaling regulates cellular protein interactions. Biochim Biophys Acta 1820, 722-9 (2012).

18. Cumming, R. C. et al. Protein disulfide bond formation in the cytoplasm during oxidative stress. J Biol Chem 279, 21749-58 (2004).

19. Jaffrey, S. R., Erdjument-Bromage, H., Ferris, C. D., Tempst, P. \& Snyder, S. H. Protein Snitrosylation: a physiological signal for neuronal nitric oxide. Nat Cell Biol 3, 193-7 (2001).

20. Wang, X., Kettenhofen, N. J., Shiva, S., Hogg, N. \& Gladwin, M. T. Copper dependence of the biotin switch assay: modified assay for measuring cellular and blood nitrosated proteins. Free Radic Biol Med 44, 1362-72 (2008).

21. Saurin, A. T., Neubert, H., Brennan, J. P. \& Eaton, P. Widespread sulfenic acid formation in tissues in response to hydrogen peroxide. Proc Natl Acad Sci U S A 101, 17982-7 (2004).

22. Lind, C. et al. Identification of S-glutathionylated cellular proteins during oxidative stress and constitutive metabolism by affinity purification and proteomic analysis. Arch Biochem Biophys 406, 229-40 (2002).

23. Leichert, L. I. et al. Quantifying changes in the thiol redox proteome upon oxidative stress in vivo. Proc Natl Acad Sci U S A 105, 8197-202 (2008).

24. Le Moan, N., Clement, G., Le Maout, S., Tacnet, F. \& Toledano, M. B. The Saccharomyces cerevisiae proteome of oxidized protein thiols: contrasted functions for the thioredoxin and glutathione pathways. J Biol Chem 281, 10420-30 (2006).

25. Baty, J. W., Hampton, M. B. \& Winterbourn, C. C. Proteomic detection of hydrogen peroxide-sensitive thiol proteins in Jurkat cells. Biochem J 389, 785-95 (2005).

26. Delahunty, C. \& Yates, J. R., 3rd. Protein identification using 2D-LC-MS/MS. Methods 35, 248-55 (2005).

27. Hao, G., Derakhshan, B., Shi, L., Campagne, F. \& Gross, S. S. SNOSID, a proteomic method for identification of cysteine S-nitrosylation sites in complex protein mixtures. Proc Natl Acad Sci U S A 103, 1012-7 (2006). 
28. Sinha, V. et al. Proteomic and mass spectroscopic quantitation of protein S-nitrosation differentiates NO-donors. ACS Chem Biol 5, 667-80 (2010).

29. Foster, M. W. Methodologies for the characterization, identification and quantification of Snitrosylated proteins. Biochim Biophys Acta 1820, 675-83 (2012).

30. Bechtold, E. \& King, S. B. Chemical methods for the direct detection and labeling of Snitrosothiols. Antioxid Redox Signal 17, 981-91 (2012).

31. Martinez-Acedo, P. et al. A novel strategy for global analysis of the dynamic thiol redox proteome. Mol Cell Proteomics 11, 800-13 (2012).

32. Gygi, S. P. et al. Quantitative analysis of complex protein mixtures using isotope-coded affinity tags. Nat Biotechnol 17, 994-9 (1999).

33. Sethuraman, M. et al. Isotope-coded affinity tag (ICAT) approach to redox proteomics: identification and quantitation of oxidant-sensitive cysteine thiols in complex protein mixtures. J Proteome Res 3, 1228-33 (2004).

34. Sethuraman, M. et al. Quantification of oxidative posttranslational modifications of cysteine thiols of p21ras associated with redox modulation of activity using isotope-coded affinity tags and mass spectrometry. Free Radic Biol Med 42, 823-9 (2007).

35. Sethuraman, M., McComb, M. E., Heibeck, T., Costello, C. E. \& Cohen, R. A. Isotopecoded affinity tag approach to identify and quantify oxidant-sensitive protein thiols. Mol Cell Proteomics 3, 273-8 (2004).

36. Fu, C. et al. Quantitative analysis of redox-sensitive proteome with DIGE and ICAT. J Proteome Res 7, 3789-802 (2008).

37. Garcia-Santamarina, S. et al. The oxidized thiol proteome in fission yeast--optimization of an ICAT-based method to identify H2O2-oxidized proteins. J Proteomics 74, 2476-86 (2011).

38. Garcia-Santamarina, S. et al. Is oxidized thioredoxin a major trigger for cysteine oxidation? Clues from a redox proteomics approach. Antioxid Redox Signal 18, 1549-56 (2013).

39. Brandes, N., Reichmann, D., Tienson, H., Leichert, L. I. \& Jakob, U. Using quantitative redox proteomics to dissect the yeast redoxome. J Biol Chem 286, 41893-903 (2011). 
40. Kumsta, C., Thamsen, M. \& Jakob, U. Effects of oxidative stress on behavior, physiology, and the redox thiol proteome of Caenorhabditis elegans. Antioxid Redox Signal 14, 102337 (2011).

41. Knoefler, D. et al. Quantitative in vivo redox sensors uncover oxidative stress as an early event in life. Mol Cell 47, 767-76 (2012).

42. Christoforou, A. L. \& Lilley, K. S. Isobaric tagging approaches in quantitative proteomics: the ups and downs. Anal Bioanal Chem 404, 1029-37 (2012).

43. Boersema, P. J., Raijmakers, R., Lemeer, S., Mohammed, S. \& Heck, A. J. Multiplex peptide stable isotope dimethyl labeling for quantitative proteomics. Nat Protoc 4, 484-94 (2009).

44. Guo, J. et al. Resin-assisted enrichment of thiols as a general strategy for proteomic profiling of cysteine-based reversible modifications. Nat Protoc 9, 64-75 (2014).

45. Hansen, R. E. \& Winther, J. R. An introduction to methods for analyzing thiols and disulfides: Reactions, reagents, and practical considerations. Anal Biochem 394, 147-58 (2009).

46. Gilbert, H. F. Thiol/disulfide exchange equilibria and disulfide bond stability. Methods Enzymol 251, 8-28 (1995).

47. Rogers, L. K., Leinweber, B. L. \& Smith, C. V. Detection of reversible protein thiol modifications in tissues. Anal Biochem 358, 171-84 (2006).

48. Held, J. M. \& Gibson, B. W. Regulatory control or oxidative damage? Proteomic approaches to interrogate the role of cysteine oxidation status in biological processes. Mol Cell Proteomics 11, R111 013037 (2012).

49. Sivaraman, T., Kumar, T. K., Jayaraman, G. \& Yu, C. The mechanism of 2,2,2trichloroacetic acid-induced protein precipitation. J Protein Chem 16, $291-7$ (1997).

50. Bensadoun, A. \& Weinstein, D. Assay of proteins in the presence of interfering materials. Anal Biochem 70, 241-50 (1976).

51. Rajalingam, D., Loftis, C., Xu, J. J. \& Kumar, T. K. Trichloroacetic acid-induced protein precipitation involves the reversible association of a stable partially structured intermediate. Protein Sci 18, 980-93 (2009). 
52. Boja, E. S. \& Fales, H. M. Overalkylation of a protein digest with iodoacetamide. Anal Chem 73, 3576-82 (2001).

53. Gundlach, H. G., Moore, S. \& Stein, W. H. The reaction of iodoacetate with methionine. J Biol Chem 234, 1761-4 (1959).

54. Lapko, V. N., Smith, D. L. \& Smith, J. B. Identification of an artifact in the mass spectrometry of proteins derivatized with iodoacetamide. J Mass Spectrom 35, 572-5 (2000).

55. Crestfield, A. M., Stein, W. H. \& Moore, S. Alkylation and identification of the histidine residues at the active site of ribonuclease. J Biol Chem 238, 2413-9 (1963).

56. Park, S. S. et al. Effective correction of experimental errors in quantitative proteomics using stable isotope labeling by amino acids in cell culture (SILAC). J Proteomics 75, 3720-32 (2012).

57. Cox, J. et al. Andromeda: a peptide search engine integrated into the MaxQuant environment. J Proteome Res 10, 1794-805 (2011).

58. Wisniewski, J. R., Zougman, A. \& Mann, M. Combination of FASP and StageTip-based fractionation allows in-depth analysis of the hippocampal membrane proteome. J Proteome Res 8, 5674-8 (2009).

59. Gouw, J. W. \& Krijgsveld, J. MSQuant: a platform for stable isotope-based quantitative proteomics. Methods Mol Biol 893, 511-22 (2012).

60. Mortensen, P. et al. MSQuant, an open source platform for mass spectrometry-based quantitative proteomics. J Proteome Res 9, 393-403 (2010).

61. Kruger, R., Hung, C. W., Edelson-Averbukh, M. \& Lehmann, W. D. lodoacetamidealkylated methionine can mimic neutral loss of phosphoric acid from phosphopeptides as exemplified by nano-electrospray ionization quadrupole time-of-flight parent ion scanning. Rapid Commun Mass Spectrom 19, 1709-16 (2005).

62. Hung, C. W., Schlosser, A., Wei, J. \& Lehmann, W. D. Collision-induced reporter fragmentations for identification of covalently modified peptides. Anal Bioanal Chem 389, 1003-16 (2007). 


\section{FIGURE LEGENDS}

Figure 1 | Schematic representation of the gel-free strategy to identify and quantify oxidized cysteines using the ICAT technology in a proteomic scale. TCA extracts are prepared from two conditions to be compared (condition 1 and condition 2). Thiols (-SH) in the extracts are alkylated with IAM. Upon reduction of reversibly oxidized thiols (-SSR) with TCEP, resulting thiols (-SH) are alkylated with either light $\left(B-{ }^{12} \mathrm{C}-\mathrm{IAM}\right.$, condition 1$)$ or heavy $\left(\mathrm{B}-{ }^{13} \mathrm{C}-\mathrm{IAM}\right.$, condition 2$)$ ICAT reagents. Labelled protein extracts are then mixed and digested with trypsin. ICAT-labelled peptides are affinity-purified with streptavidin beads, fractionated by liquid chromatography and analyzed by liquid chromatography and mass spectrometry (LC-MS/MS). To quantify individual proteins by dimethyl labelling (DM), small fractions of protein extracts are digested with trypsin, and resulting peptides are labelled at their amino groups $\left(-\mathrm{NH}_{2}\right)$ with medium $(\mathrm{D}-\mathrm{CDO}$, condition 1$)$ or heavy (D-

${ }^{13} \mathrm{CDO}$, condition 2) formaldehyde. Resulting peptides are mixed, fractionated by liquid chromatography and analyzed by mass spectrometry (LC-MS/MS).

Figure 2 | Performance of the ICAT-based biotin switch assay combined with dimethyl (DM) labelling to characterize the reversibly-oxidized thiol proteome of S. pombe. (a) Monitoring step: labelling of reversibly oxidized cysteines by $1 \mathrm{D}$ electrophoresis. Free thiols in TCA protein extracts of untreated (-) or treated $\left(0.2 \mathrm{mM} \mathrm{H}_{2} \mathrm{O}_{2}\right.$ for $30 \mathrm{sec}$; $\left.\mathrm{H}\right)$ wild-type cells, or from cells lacking thioredoxin $(\Delta t r x 1)$ or thioredoxin reductase $(\Delta t r r 1)$ were alkylated with IAM. Upon reduction of oxidized thiols, resulting thiols were alkylated with a fluorescently labelled IAM derivative. Samples were analyzed by fluorescent 1D gel electrophoresis (oxidized thiols) and with silver staining, as a control of protein loading. (b) Representation of the log 2 frequency distribution of the ICAT and DM ratios for the condition $\Delta t r r 1$ untreated vs wild-type untreated, before (left panel) and after (right panel) data normalization. ICAT: data from three biological replicates with two technical replicates each. DM: data from one biological replicate. (c) Illustration of the overlap between ICAT ratios in two biological replicates, with two technical replicates each, obtained by comparing two conditions, $\Delta$ trx1 untreated vs wild-type untreated cells. (d) Percentages of peptides with oxidized thiols obtained by combining ICAT and DM labelling data in two biological replicates, with two technical 
replicates each, for the three compared environmental or genetic conditions of S. pombe: extracts from $0.2 \mathrm{mM} \mathrm{H}_{2} \mathrm{O}_{2}$ treated wild-type cells $\left(\mathrm{H}_{2} \mathrm{O}_{2}\right)$ or from cells lacking Trx1 ( $\Delta$ trx1) or Trr1 ( $\Delta$ trr1). 


\section{LIST SUPPLEMENTARY INFORMATION}

García-Santamarina et al. 2014

Supplementary Fig. 1. TCA followed by IAM, but not only IAM, is required to display the transient $\mathrm{H} 2 \mathrm{O} 2-d e p e n d e n t$ in vivo oxidation of Pap1.

Supplementary Fig. 2. Effect of SDS and Tris- $\mathrm{HCl}$ in the labelling of oxidized cysteines and proteins in their N-terminal sites.

Supplementary Table 1 - Peptides with oxidized cysteines (ICAT ratio vs protein concentration $>1.5$ in two biological replicates) identified from wild-type $\mathrm{H}_{2} \mathrm{O}_{2}$-treated vs wild-type untreated fission yeast cells

Supplementary Table 2 - Peptides with oxidized cysteines (ICAT ratio vs protein concentration $>1.5$ in two biological replicates) identified from $\Delta$ trr1 vs wild-type untreated fission yeast cells

Supplementary Table 3 - Peptides with oxidized cysteines (ICAT ratio vs protein concentration $>1.5$ in two biological replicates) identified from $\Delta t r x 1$ vs wild-type untreated fission yeast cells

Supplementary Data 1. Description LC gradient with 84 min (marked '120 minutes') and 147 min (marked '180 minutes') resolving gradients.

Supplementary Data 2. MS and MS/MS parameters for a Q-Exactive mass spectrometer operated in data dependent (dd) mode.

Supplementary Data 3. Retention time comparison of identical cysteine-containing peptides modified by carbamidomethyl (ca) and/or ICAT measured in the same experiment.

Supplementary Data 4. MS/MS spectra of the triply charged peptide

Supplementary Data 5. MS spectrum of the triply charged peptide.

Supplementary Data 6. Three dimensional plot of the ICAT-labelled peptide pair shown in Supplementary Data 5.

Supplementary Data 7. Modifications used to search tandem MS data (MS/MS).

Supplementary Data 8. Five important steps needed to launch a MaxQuant 1.3.0.5 analysis.

Supplementary Data 9. The 'peptide.txt' file contains the dimethyl-based quantification results as well as the ICAT-based quantification results.

Supplementary Data 10 . Scatter plot of measured ICAT ratios. 

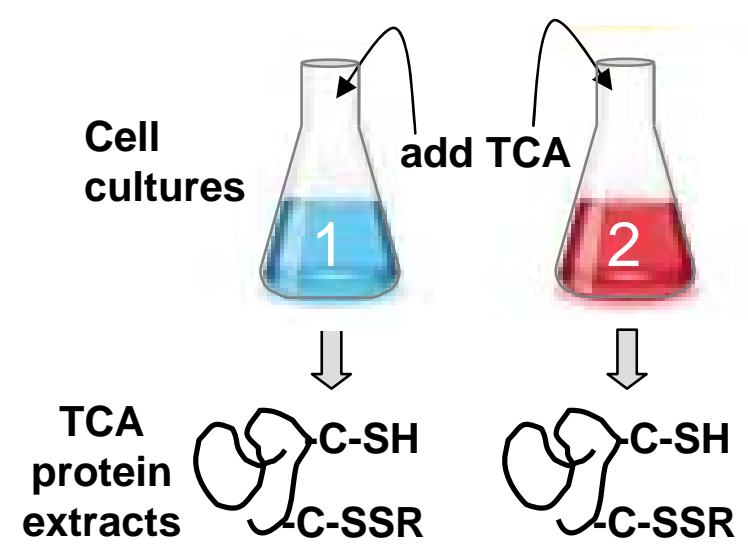

IAM

\IAM

$\bigcup_{C-S S R}^{C-S I A M}$

TCEP<smiles>[Si]C1C(S)CC2CCC1CC2</smiles>

B- ${ }^{12} \mathrm{C}-\mathrm{IA}$

(light-ICAT)

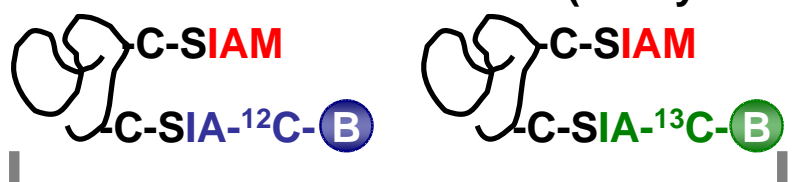

trypsin digest
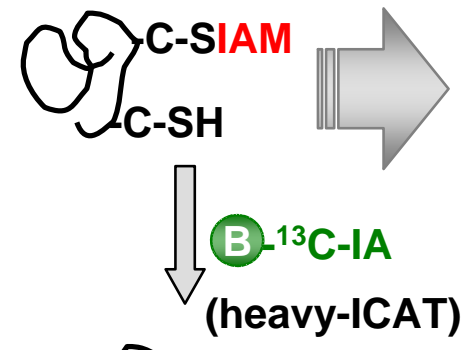

$\bigcup_{C-S S R}^{C-S I A M}$

TCEP

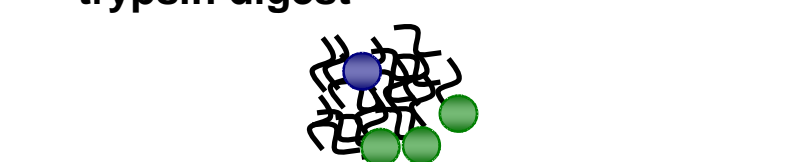

avidin affinity

enrichment

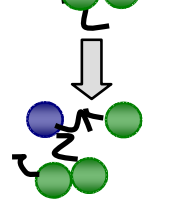

LC-MS/MS

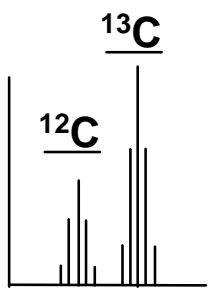

Cys oxidation ratio

in 2 versus 1
Dimethyl protein quantitation

Q

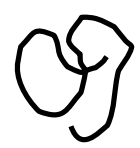

pro.ext. 1 pro.ext. 2

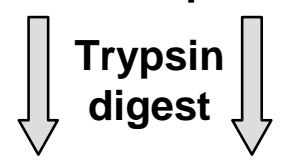

每

D-CDO

(medium

labelling) $\checkmark$

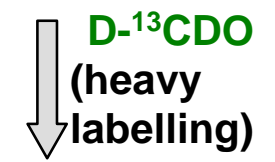

$\mathrm{NC}_{2} \mathrm{D}_{4} \mathrm{H}_{2}$

$\underbrace{\text { Nity }}_{\text {mix }}$

LC-MS/MS

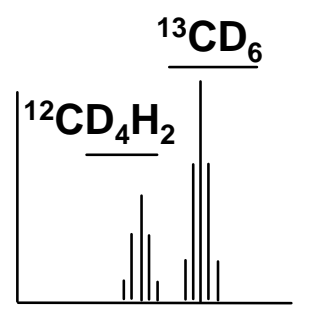

protein ratio

in 2 versus 1 
a

electrophoresis

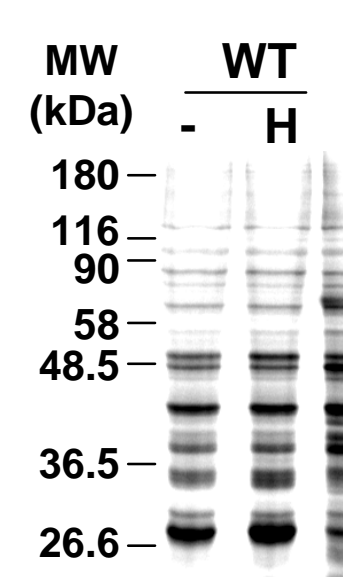

Oxidized thiols

b Non-normalized data

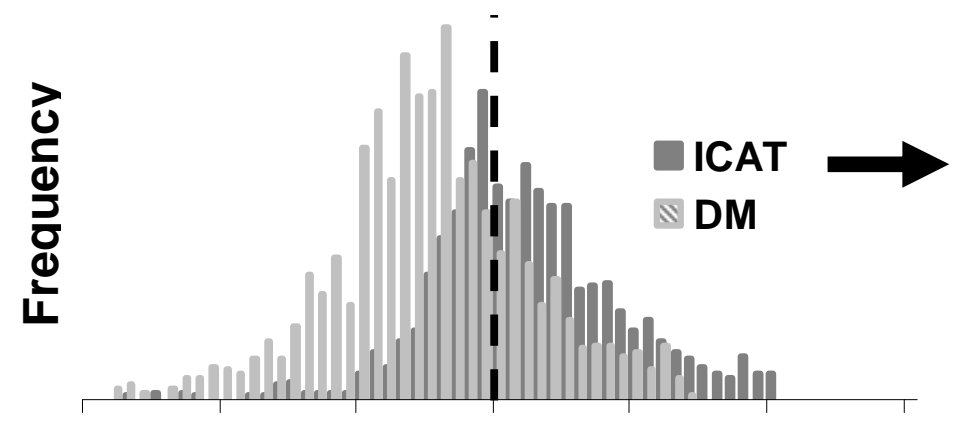

$\frac{W T}{-H} \nabla^{\Delta} \nabla^{s}$

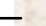

$=$

$-$

Silver staining

Normalized data

$-3$

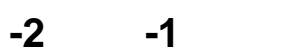

1

$\begin{array}{lll}2 & 3 & -3\end{array}$

$-2$

$-1$

$0 \quad 1$

2 3

ICAT or dimethyl (DM) log 2 ratios $\Delta$ trr1 untreated vs WT untreated

ICAT or dimethyl (DM) log 2 ratios $\Delta$ trr1 untreated vs WT untreated

C

Biol.

Repl \#1

511 pept.

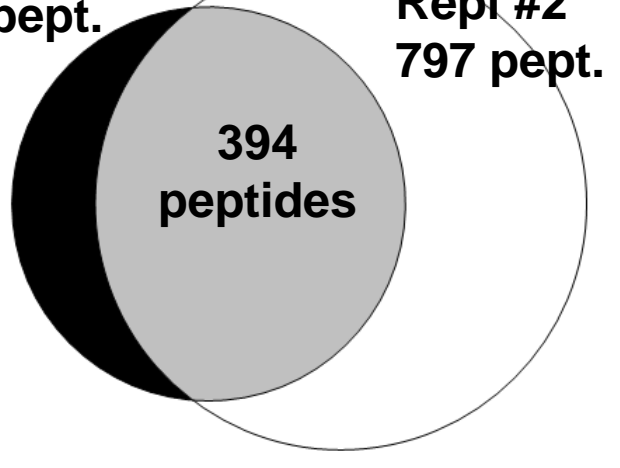

ICAT ratios

Biol.

Repl \#2

797 pept.

394

eptides

$\Delta$ trx1 untreated vs WT untreated

d Proteomic data

ICAT and DM labelling
ICAT

DM

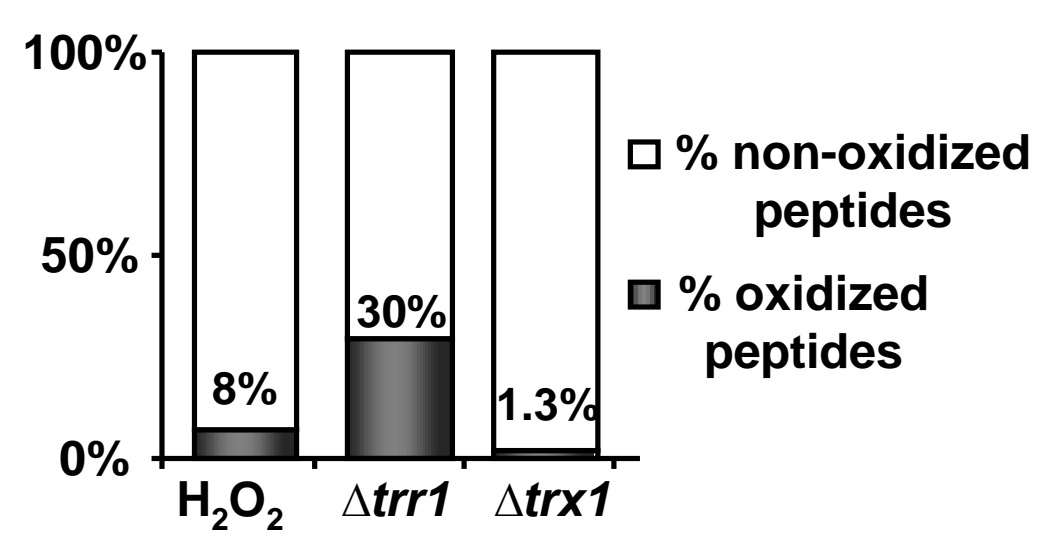

